(C) 2019 Universidad Nacional Autónoma de México, Facultad de Estudios Superiores Zaragoza.

Este es un artículo Open Access bajo la licencia CC BY-NC-ND (http://creativecommons.org/licenses/by-nc-nd/4.0/).

TIP Revista Especializada en Ciencias Químico-Biológicas, 22: 1-11, 2019.

DOI: $10.22201 /$ fesz.23958723e.2019.0.190

\title{
Tendencias de la bioenergía: del metagenoma de hábitats ricos en azufre a la purificación del biogás
}

\author{
*FabiolaVeana, Perla Yanet González-Purata, Jorge Enrique Wong-Paz, \\ Pedro Aguilar-Zárate y Diana B. Muñiz-Márquez \\ Departamento de Ingenierías, Tecnológico Nacional de México Campus Ciudad Valles, \\ Carretera al Ingenio Plan de Ayala Km. 2, Ciudad Valles 79010, San Luis Potosí, México \\ E-mail: *fabiola.veana@tecvalles.mx
}

\begin{abstract}
RESUMEN
Gran cantidad de residuos generados por la agroindustria son considerados tanto para la obtención de productos útiles de mayor valor agregado como para reducir el impacto ambiental. Existen alternativas para evaluar estos desechos siendo la producción de bioenergía una solución de gran precedente, desde la producción de biodiesel, bioetanol y biogás hasta aprovechar la biomasa. La producción de biogás por metanogénesis es una alternativa para la generación de biocombustibles y energía. Sin embargo, surge un problema que puede generar daños en la planta industrial durante la producción del biogás, cuando se inhibe su proceso fermentativo por la presencia tóxica del sulfuro de hidrógeno y se presenta un aumento en la emisión de SOx (en concentraciones de hasta 658 ppmv). Dentro de los métodos de remoción de este compuesto se encuentra el biológico, a través de microorganismos por oxidación. El objetivo de esta revisión es exponer las tendencias del uso de microorganismos oxidantes de azufre en biotecnología ambiental, particularmente el papel de éstos en la purificación del biogás.

Palabras Clave: microorganismos oxidantes del azufre, biometano, metagenómica, purificación biológica, residuos agroindustriales.
\end{abstract}

Trends in bioenergy: from the metagenoma of habitats rich in sulfur to the purification of biogas

\begin{abstract}
A large amount of wastes is generated by agro-industry and can be valorized to obtain useful products with higher added value, thus reducing environmental impact. There are alternatives to valorize these wastes and the production of bioenergy has been a great precedent, from the production of biodiesel, bioethanol and biogas that is possible by the use of biomass. Biogas production by methanogenesis is an alternative for the generating biofuels and energy. However, a problem arises during biogas production due to the presence of hydrogen sulfide (and other compounds), which is toxic and can damage the biogas plant (up concentrations of $658 \mathrm{ppmv}$ ), increase SOx emissions and inhibit the fermentation process of biogas production, so it is necessary to eliminate them. The biological removal method of this compound is included, by oxidization through microorganisms. The objective of this review is to expose the trends in the use of the microorganisms mentioned in environmental biotechnology, particularly their role in biogas purification.
\end{abstract}

Key Words: agroindustrial wastes, biological purification, biomethane, metagenomics, sulfur oxidizing microorganisms. 


\section{INTRODUCCIÓN}

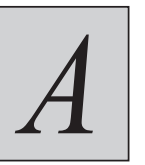

nivel mundial, las actividades agroindustriales han aumentado debido a su constante desarrollo, lo que ha generado una alarmante cantidad de residuos sólidos. Los más conocidos son los producidos por la industria alimentaria y no alimentaria, así como las facilitadoras y consumidoras de materia prima. A pesar de que éstos pueden ser aprovechados como alimento para animales o revalorizados para la extracción de compuestos bioactivos y otras aplicaciones en la industria, desafortunadamente las empresas no cuentan con planes estratégicos para ello, debido a su alto costo (Vargas-Corredor \& Pérez-Pérez, 2018; Yepes, Naranjo \& Sánchez, 2008). Tan solo la industria del café, del papel y el aceite de palma desechan más del 70\% de la materia prima, que está compuesta por pectina, celulosa, almidón y lignina, entre otros (Grande-Tovar, 2016). Por lo tanto, el conjunto de estos residuos agroindustriales (sólidos y líquidos), es conocido como biomasa; y las nuevas formas de aprovecharla es para la producción de bioenergía. Así, los residuos sólidos generan electricidad y los líquidos han sido evaluados como biocombustibles (biodiesel, bioetanol y biogás) (Vargas-Corredor \& Pérez-Pérez, 2018). Por su naturaleza, representan una ventaja sobre los combustibles fósiles al ser formas de energía renovables. Ante ello, el biogás es alternativo al gas natural y se genera mediante la digestión anaeróbica de algunos residuos orgánicos provenientes, principalmente de plantas industriales. El biogás es una mezcla de gases metano (o biometano, $\mathrm{CH}_{4}$ ) y dióxido de carbono $\left(\mathrm{CO}_{2}\right)$ con menores porcentajes de vapor de agua, hidrógeno y sulfuro de hidrógeno (o ácido sulfhídrico, $\mathrm{H}_{2} \mathrm{~S}$ ), este último junto con el $\mathrm{CO}_{2}$ son removidos al purificarse el biogás obteniendo $\mathrm{CH}_{4}$ (Guo, Song \& Buhain, 2015). Para obtener biogás puro, las opciones de oxidación o eliminación del $\mathrm{H}_{2} \mathrm{~S}$ son por métodos químicos y biológicos. Los métodos químicos contaminan en mayor proporción al medio ambiente, por lo tanto, el uso de microrganismos oxidantes de azufre o SOM (sulfur oxidizing microorganisms) ha sido una buena alternativa. Las responsables de esta acción, son las bacterias quimiolitotróficas del género Thiobacillus, Sulfolobus, Thermotrix, Beggiatoa y Thiothrix (Rubiano-Labrador, Hurtado \& Salamanca, 2018). Por lo tanto, la presente revisión tiene como objetivos: exponer las tendencias actuales del uso de los SOM que impactan en la obtención de bioenergía a partir de residuos agroindustriales, conocer su metabolismo, su identificación por metagenómica y el rol que juegan en la purificación del biogás.

\section{Agroindustria: ACTIVIdades agrícolas Y ECONOMÍA}

Las actividades agroindustriales tienen un impacto en el desarrollo de cualquier país pues representan cierta parte del producto interno bruto. Los sectores como la agricultura, ganadería, silvicultura, así como la pesca, son de importancia económica en México (Basurto \& Escalante, 2012). En lo que respecta al sector de la agricultura, la producción de frutas y hortalizas tienen mayor dinamismo debido a las exportaciones que se realizan, siendo en menor medida los cereales (arroz, trigo y sorgo), caña de azúcar, café y leguminosas. En tanto, el maíz lidera la lista de los principales cultivos en México, representando más del $50 \%$ de la superficie. Por otro lado, la ganadería engloba la producción de carne de bovino, cerdo, pollo, huevos de gallina y leche de vaca, siendo la de mayor relevancia la primera en términos de porcentaje de producción $(>29 \%)$, (Escalante \& Catalán, 2008). Para los países en desarrollo, la agricultura es de suma importancia y en nuestro país existen dos tipos de prototipos económicos: en el primero, los pequeños productores cultivan, cosechan o utilizan el campo en beneficio propio, ya sea para obtener ingresos económicos o para su alimentación. (Quirino, Duana, Hernández \& García, 2016).

\section{GENERACIÓN DE RESIDUOS AGROINDUSTRIALES}

La agroindustria genera y fomenta el desarrollo económico y social del entorno; por lo que las materias primas son sometidas a procesos de adecuación o transformación para otorgarles un valor agregado mediante operaciones unitarias y facilitar su consumo. Sin embargo, se genera uno de los principales problemas ambientales: la alta producción de residuos. En algunos casos, estos son tratados hasta reducir el impacto negativo que su emisión, vertimiento o disposición pudieran generar convirtiéndolos en un producto útil y de mayor valor agregado que solucione el problema y genere ingresos económicos adicionales (Cury et al., 2017). Los compuestos de interés de estos residuos o subproductos presentan aplicaciones alimentarias, cosméticas, farmacéuticas y biotecnológicas (Vargas-Corredor \& PérezPérez, 2018) con ventajas para la industria generadora de residuos y para el medio ambiente, puesto que estos residuos contienen compuestos fenólicos o tóxicos que causan daños al agua, flora y fauna del lugar donde se descarguen o depositen sin un tratamiento previo. Además de compuestos bioactivos, los residuos agroindustriales contienen azúcares, proteínas, minerales, pectina y materiales lignocelulósicos como celulosa, hemicelulosa y lignina (Mussatto, Ballesteros, Martins \& Teixeira, 2012).

En México, los principales residuos agroindustriales son generados por el área agrícola, desde cáscaras de frutas y vegetales, hojas de maíz, hasta bagazo de caña de azúcar, maguey y agave, pulpa de café, paja de trigo, cebada y frijol entre otros (Mejías-Brizuela, Orozco-Guillén \& Galáan-Hernández, 2016). Los números señalan que en las agroindustrias se aprovechan bajos porcentajes de la biomasa. En la industria cervecera se aprovecha el $8 \%$ de los nutrientes del grano, en la del aceite de palma un $9 \%$, en la del café el $9.5 \%$ del peso del fruto fresco. Mientras que en otras cerca del $30 \%$ como en la de celulosa y en la del papel, por mencionar algunas (Cury et al., 2017). En el caso de la ganadera, los 
residuos son principalmente estiércol (Mejías-Brizuela et al., 2016) utilizado para abonos orgánicos, mediante mezclas de cachaza y bagazo de caña de azúcar con diferentes fuentes de estiércol (Palma-López, Zavala-Cruz, Cámara-Reyna, Ruiz-Maldonado \& Salgado-García, 2016); también en la producción de nano-celulosa a partir de la cáscara y pulpa de residuos cítricos (Naz et al., 2016); extracción de compuestos bioactivos de la cáscara de los cítricos como la lima (Padilla de la Rosa et al., 2018), pectina a partir del bagazo de lima (Sanchez-Aldana, Aguilar, Nevarez-Moorillon \& Esquivel-Contreras, 2013) y los polifenoles obtenidos de las cáscaras de mandarina (Safdar et al., 2017). Sin embargo, la tendencia actual se inclina por la producción de bioenergía y biocombustibles, por ejemplo la obtención del biogás a partir de lacto-suero y estiércol de vaca, entre otros (Hublin, Schneider \& Dzodan, 2014).

\section{DEMANDA ENERGÉTICA}

¿Te has puesto a pensar en la cantidad de energía que se utiliza para elaborar un vaso que contiene tu café de las mañanas? ¿Cuánta energía gastas para dormir en una habitación fresca a $22{ }^{\circ} \mathrm{C}$ ? Los tipos de energía más utilizados hasta la fecha para satisfacer las necesidades energéticas de la población son a partir de fósiles (no renovables), energía nuclear y por energías renovables. Los depósitos de energía a partir de residuos fósiles por cientos de años se han utilizado, pero no son renovables y en algún momento se agotarán las reservas, se elevará su costo, el calentamiento global llegará a su límite y dejarán de ser rentables (Asif \& Muneer, 2007). Desde 2011, se han reportado incrementos en los precios del gas natural, petróleo y carbón en más del 120\%, 370\% y 460\%, respectivamente (Castro, 2011). En tanto, países como China, India, Rusia, Reino Unido y Estados Unidos de Norteamérica (USA) necesitarán más fuentes de energía en un futuro cercano (Asif \& Muneer, 2007). Ante ello, el Foro Económico Mundial consideró como una solución a este problema el uso de biorefinerías para cumplir con la demanda energética mundial utilizando la biomasa para generar combustibles y materiales, entre otros (Diep et al., 2012).

A nivel mundial la tendencia del crecimiento poblacional es alto, pues se estima que para el 2050 serán más de 9 billones de habitantes, comparado a los 7.3 billones, aproximadamente, que existen actualmente. Ante este panorama, las necesidades de energía serán más demandantes y las consecuencias en el medio ambiente por las emisiones de $\mathrm{CO}_{2}$ a la atmósfera serán inimaginables. Tan solo para el 2035, se considera que más de 17 billones de toneladas equivalentes de petróleo serán necesarias para abastecer las necesidades de la población (Chu \& Majumdar, 2012).

\section{BIOENERGÍA Y BIOCOMBUSTIBLES}

A través del petróleo o gas natural se produce aproximadamente el $88 \%$ de la energía mundial (Achinas,
Achinas \& Euverink, 2017). Por lo tanto, las opciones para sustituirlo paulatinamente han sido la implementación de biorefinerías con la finalidad de generar bioenergía a partir de la biomasa (Vargas-Corredor \& Pérez-Pérez, 2018). Como fuente renovable, la bioenergía es producida a partir de la materia orgánica, principalmente de residuos agroindustriales. Los principales productos son biocombustibles como el bioetanol y el biodiesel, los cuales pueden ser utilizados para fines de transportación, su producción a base de fermentación por levaduras y de aceites comestibles y no comestibles, grasas animales y algunos residuos agroindustriales como plantas, respectivamente, los hacen más ventajosos que los combustibles fósiles (Rasool \& Hemalatha, 2016). Por otro lado, no sólo se producen combustibles líquidos como el bioetanol y el biodiesel, sino también existen formas sólidas como las virutas de madera y gaseosas como el biogás, este último es obtenido por digestión anaeróbica (Singh \& Walia, 2016).

Algunos estudios se han llevado a cabo para la obtención de biocombustibles como lo señalan Ingale, Joshi \& Gupte (2014), quienes utilizaron residuos de banana como sustrato celulósico para la producción de bioetanol. Mediante el uso de pre-tratamientos alcalinos y de sacarificación por Aspergillus ellipticus y Aspergillus fumigatus seguido de una fermentación por Saccharomyces cerevisiae se logró la producción de 17.1 $\mathrm{g} / \mathrm{L}$ de etanol con un rendimiento del $84 \%$. En otro sentido, Hossain \& Mekhled (2010), utilizaron residuos de aceite de canola empleado para cocinar alimentos en relación 1:1 con metanol, así como hidróxido de sodio $0.5 \%$ por transesterificación a temperatura de $55^{\circ} \mathrm{C}$ y $250 \mathrm{rpm}$ para producir biodiesel, con un rendimiento del $49.5 \%$.

\section{ProducCión de biogás}

El biogás es obtenido por la degradación bacteriana de la biomasa en condiciones anaeróbicas. En términos de composición química, el principal compuesto de interés es el $\mathrm{CH}_{4}(50-75 \%)$, sin embargo, el biogás también contiene $\mathrm{CO}_{2}(25-50 \%)$ y otros elementos como agua, oxígeno $\left(\mathrm{O}_{2}\right)$, $\mathrm{H}_{2} \mathrm{~S}$ y azufre elemental (S). Para la obtención del biogás por digestión anaerobia a partir de material orgánico, se presenta la reacción general $\mathrm{C}_{6} \mathrm{H}_{12} \mathrm{O}_{6} \rightarrow 3 \mathrm{CO}_{2}+3 \mathrm{CH}_{4}$ y se realiza en cuatro etapas: primero se realiza una hidrólisis, seguida de una acidificación (acidogénesis), producción de ácido acético (acetogénesis) y de biometano (metanogénesis) (Gómez, 2013). Durante la hidrólisis, se descompone la materia orgánica en condiciones de ausencia de oxígeno mediante microorganismos (bacterias anaerobias) como Bacteriocides, Clostridia, Bifidobacteria, Streptococci y Enterobacteriaceae. En cambio, en la acidogénesis ocurre la conversión de moléculas orgánicas simples a $\mathrm{CO}_{2}, \mathrm{H}_{2}$, ácidos orgánicos, así como amoniaco $\left(\mathrm{NH}_{3}\right)$ por bacterias acidogénicas. Por otro lado, en la acetogénesis se convierten los ácidos orgánicos en ácido acético $\left(\mathrm{CH}_{3} \mathrm{COOH}\right)$, así como $\mathrm{H}_{2}, \mathrm{NH}_{3}$ y $\mathrm{CO}_{2}$, mediada por bacterias acetogénicas. Finalmente, en el proceso de 
metanogénesis se descompone el $\mathrm{CH}_{3} \mathrm{COOH}$ a $\mathrm{CH}_{4}$ y $\mathrm{CO}_{2}$ por acción de bacterias metanogénicas (Guo et al., 2015). Es importante realizar un pretratamiento del sustrato o materia orgánica a utilizar con la finalidad de mejorar la digestibilidad equivalente a la reducción de su tamaño, tratamiento térmico o químico (Forster-Carneiro, Isaac, Pérez \& Schvartz, 2012).

Al ser el biogás de naturaleza renovable, como combustible gaseoso es una alternativa a varios problemas a nivel mundial, por ejemplo, su uso con la subsecuente disminución del uso de gas natural, es garantía por ser utilizado desde hace siglos (Singh \& Walia, 2016). Además, sus aplicaciones abarcan desde biogás para estufas, calentadores, energía eléctrica y motores, con la ventaja de que a partir de residuos agroindustriales de frutas, hojas de maíz o estiércol de animales es posible producirlo (Vargas-Corredor \& PérezPérez, 2018). En ese sentido, México tiene el potencial para producir bioenergía. En 2013, se estimó un potencial máximo teórico de $3700 \mathrm{MW}$, incluyendo biogás, biodiesel, bioetanol, entre otros. Esto es posible debido a la gran cantidad de residuos agroindustriales o subproductos que generan las actividades agrícolas y ganaderas. Los residuos del sorgo granífero favorecen la mayor producción de biogás ( $\mu=550 \mathrm{~L} / \mathrm{Kg}$ de sólido fresco), seguido del estiércol aviar $(\mu=74-220 \mathrm{~L} / \mathrm{Kg}$ de sólido fresco y de los residuos de comida $(\mu=75-120 \mathrm{~L} / \mathrm{Kg}$ de sólido fresco) (Mejías-Brizuela et al., 2016).

Se han realizado diversos estudios con el objetivo de producir biogás mediante subproductos industriales (Tabla I). Elaiyaraju \& Partha (2016) lograron producir biogás por co-digestión anaerobia a partir de residuos obtenidos de efluentes de la industria del curtido y tapioca utilizados como sustratos, en conjunto con el lodo obtenido de los digestores anaeróbicos con actividad metanogénica. El $80 \%$ de $\mathrm{CH}_{4}$ y $20 \%$ de $\mathrm{CO}_{2}$ fueron posibles por la optimización de las condiciones de producción $\left(\mathrm{pH} 6.5\right.$, temperatura $32^{\circ} \mathrm{C}$ y concentración de sustrato $150 \mathrm{~mL} / \mathrm{L}$, mediante un diseño compuesto central a través de la metodología de superficie de respuesta (RSM). Por otro lado, Antonelli et al. (2016), utilizaron agua residual de naturaleza porcina como inóculo mediante digestión anaerobia con suero de queso a diferentes temperaturas $\left(26{ }^{\circ} \mathrm{C}\right.$ y $\left.32{ }^{\circ} \mathrm{C}\right)$ y $\mathrm{pH}(3.65$ y 3.53$)$. Sus resultados demostraron que a ambas temperaturas se puede producir biogás con rendimientos similares, siendo a $32{ }^{\circ} \mathrm{C}$ donde más se obtuvo $(270 \mathrm{~L})$, ya que el $63 \%$ corresponde al biometano, comparado con el obtenido a $26{ }^{\circ} \mathrm{C}(171 \mathrm{~L})$, donde el $61 \%$ también es biometano. Además, no se detectó amonio ni ácido sulfhídrico.

En tanto, Chakravarty (2016) evaluó la producción del biogás a partir de residuos agroindustriales, principalmente frutas (manzana, piña, naranja, bananas y yaca), previamente licuadas para disminuir el tamaño de la partícula. Se utilizaron los cinco tipos de residuos de frutas y una mezcla de todas como sustrato por digestión anaeróbica y se evaluó la carga microbiana de cada residuo. Sus resultados demostraron que la mezcla de residuos es capaz de producir mayor cantidad de biogás $(990 \mathrm{~mL})$ en comparación con el proceso individual, siendo la de mayor rendimiento los residuos de la piña $(975$ $\mathrm{mL}$ ), en un lapso de tres semanas. Se demostró que esta producción está relacionada con la carga microbiana presente

\begin{tabular}{|l|l|l|l|}
\hline \multicolumn{1}{|c|}{ Sustrato/co-sustrato } & Composición del biogás & \multicolumn{1}{c|}{$\begin{array}{c}\text { Biogás generado } \\
\text { (L) }\end{array}$} & Referencia \\
\hline $\begin{array}{l}\text { Purín de cerdo, aguas residuales (grises y } \\
\text { amarillas) y agua de pozo }\end{array}$ & n. e. & $357.5-436.2$ & (Pinto \& Quipuzco, 2015) \\
\hline $\begin{array}{l}\text { Residuos de frutas (manzana, piña, naranja, } \\
\text { bananas y yaca) }\end{array}$ & n. e. & 0.99 & (Chakravarty, 2016) \\
\hline Residuos sólidos urbanos & $\begin{array}{l}\mathrm{CH}_{4}: 33.7 \mathrm{~L} \\
\mathrm{CO}_{2}: 25.63 \mathrm{~L} \\
\mathrm{H}_{2} \mathrm{~S}: 0.24 \mathrm{~L}\end{array}$ & 63.01 & $\begin{array}{l}\text { (Tapia-Gómez, Laines-Canepa } \\
\text { \& Sosa-Olivier, 2017) }\end{array}$ \\
\hline Tapioca y lodos de digestores anaeróbicos & $\begin{array}{l}\mathrm{CH}_{4}: 80 \% \\
\mathrm{CO}_{2}: 20 \%\end{array}$ & Elaiyaraju \& Partha, 2016 \\
\hline Suero de queso y aguas residuales porcinas & $\begin{array}{l}\mathrm{CH}_{4}: 63 \% \\
\mathrm{CH}_{4}: 61.12-64.44 \% \\
\mathrm{CO}_{2}: 30.61-33.07 \% \\
\mathrm{O}_{2}: 4.11-5.81 \%\end{array}$ & $35.47-43.84$ & (Antonelli et al., 2016) \\
\hline $\begin{array}{l}\mathrm{H}_{2} \mathrm{~S}: 91.63-134.9 \mathrm{ppm} \\
\text { Excretas de borregos/ rumen y lodos }\end{array}$ & $\begin{array}{l}\text { Canepa, Sosa-Oliver \& } \\
\text { Escalante-Espinosa, 2017) }\end{array}$ \\
\hline
\end{tabular}

n. e.: no especificado.

Tabla I. Composición química del biogás producido a partir de residuos agroindustriales. 
en los residuos, pues a mayor cantidad de microorganismos mayor producción de biogás.

\section{Purificación del biogás: el PAPEL de LAS BACTERIAS OXIDANTES DEL AZUFRE}

La purificación del biogás es un proceso que tiene como objetivo obtener únicamente biometano por lo que se eliminan las impurezas de otros compuestos como los sulfuros $\left(\mathrm{H}_{2} \mathrm{~S}\right)$, $\mathrm{NH}_{3}$ y $\mathrm{CO}_{2}$, presentes al finalizar su producción (Guo et al., 2015; Ramaraj \& Dussadee, 2015). El proceso es también para mejorar el rendimiento calórico del biogás (Ramaraj \& Dussadee, 2015) y evitar la corrosión de los metales que lo transportan o lo generan por efecto del $\mathrm{H}_{2} \mathrm{~S}$, además que en conjunto con el $\mathrm{CO}_{2}$, que no es un combustible, representan un riesgo para la salud (Ponce, 2016). Se estima que el $\mathrm{H}_{2} \mathrm{~S}$ es tóxico para humanos, siendo letal a concentraciones de 300 ppmv (0.03\% v/v), (Moreno-Andrade, Moreno \& Quijano, 2019), además de ocasionar problemas en los aceites de los motores y en las tuberías de una planta de biogás, siendo el valor aceptable de hasta 658 ppmv. Sin embargo, se han registrado concentraciones de hasta 2000 ppmv durante la producción del biogás (ESAMUR, 2011; Llaneza, Moris, González Azpíroz \& González, 2010), cuya acción requerida es la purificación. Dentro de los factores que afectan la concentración de $\mathrm{H}_{2} \mathrm{~S}$ generado durante la obtención del biogás se encuentra el sustrato. Por ejemplo, cuando se utilizan vinazas, desechos sólidos municipales y suero lácteo las concentraciones del compuesto son de 1718, 2000 y 2133 ppmv, respectivamente, sin embargo, existen reportes de hasta 30,000 ppmv cuando se utilizan las vinazas como sustrato. (Barrera, Spanjers, Dewulf, Romero \& Rosa, 2013; MorenoAndrade et al., 2019).

A partir del biogás purificado se puede generar electricidad, calor y combustible con fines de transportación (Elaiyaraju $\&$ Partha, 2016). Se estima que a partir de $1 \mathrm{~m}^{3}$ del mismo se puede producir $1.9 \mathrm{~kW}^{*} \mathrm{~h}$ de energía en forma de electricidad, así como $3.8 \mathrm{~kW}^{*} \mathrm{~h}$ de calor (Hublin et al., 2014). En términos comparativos, $1 \mathrm{~m}^{3}$ de biogás al $60 \%$ de $\mathrm{CH}_{4}$ equivaldría a 0.7 $\mathrm{L}$ de gasolina, $2.4 \mathrm{~kW}$ h de electricidad, $0.6 \mathrm{~m}^{3}$ de gas natural y $1.3 \mathrm{Kg}$ de madera utilizada para producirlo (Ponce, 2016). Las técnicas utilizadas para la purificación del biogás involucran métodos para la remoción de $\mathrm{H}_{2} \mathrm{~S}$ fisicoquímicos (adsorción y absorción), métodos biotecnológicos (uso de microorganismos) y separación por membranas (zeolita natural), (Ortega-Viera et al., 2017). En el caso del $\mathrm{CO}_{2}$, se utiliza la adsorción por oscilación de presión, absorción física y química, separación por métodos criogénicos, separación por membranas y por métodos biológicos (Awe, Zhao, Nzihou, Minh \& Lyczko, 2017).

El uso de microorganismos para purificar el biogás al eliminar el $\mathrm{H}_{2} \mathrm{~S}$ presenta ventajas importantes en comparación de los demás métodos, pues resulta económico y no genera consecuencias dañinas al medio ambiente. En este contexto, las bacterias han sido mayormente estudiadas y en menor proporción las microalgas (Abatzoglou \& Boivin, 2009). Entre las bacterias oxidantes del azufre (del inglés Sulfur Oxidant Bacteria "SOB", se han reportado los géneros Bacillus, Thiobacillus, Beggiatoa, Thiothrix, Thermothix, Thiovolum, Acidianus, Sulfolobus, Thioalcalimicrobium y Thioalkallividrioson (Gholipour et al., 2018). La importancia del uso de estas bacterias es la capacidad para trasformar el $\mathrm{H}_{2} \mathrm{~S}$ a S elemental o en forma de $\mathrm{SO}_{4}{ }^{-2}$, sus requerimientos nutricionales son mínimos y con ello se puede separar con facilidad el azufre de la biomasa (Abatzoglou \& Boivin, 2009). Por lo tanto, se removerá el $\mathrm{CO}_{2}$ y se eliminará el $\mathrm{H}_{2} \mathrm{~S}$, enriqueciendo la producción de biometano. La biodesulfuración (oxidación del azufre), puede ser posible utilizando soportes como biolavadores, biofiltros de lecho fijo y de lecho escurrido en donde las bacterias puedan estar suspendidas o inmovilizadas para realizar dicha función (Ortega, Rodríguez, Fernández \& Bárcenas, 2015). Para ello, los biofiltros empacados con fibras naturales han sido los más utilizados (Díaz-Rodríguez et al., 2017).

Recientemente se trabajó con la biodesulfuración del biogás mediante el acoplamiento de una columna de absorción y un biorreactor de columna de burbujeo, en donde se observó la remoción de hasta el $80 \%$ de $\mathrm{H}_{2} \mathrm{~S}$ usando como inóculo una comunidad microbiana de lodo activado de una planta de tratamiento de aguas residuales municipales de Valencia, España. Dentro de la comunidad microbiana se identificaron tres proteobacterias responsables de la oxidación del azufre: Thioalkalimicrobium cyclicum, Stappia sp. y Ochrobactrum sp. (San-Valero et al., 2019). Se han reportado resultados similares de biodesulfuración del biogás usando una columna de absorción acoplada a un reactor tipo air-lift con lodo activado de la planta de tratamiento de aguas residuales "Santa Rosa" como inóculo. Dentro de los microorganismos responsables se encuentran los del filo Actinobacteria, Bacteroidetes, Firmicutes y Proteobacterias, con diferencias en abundancia relativa al inicio y tras 46 días de fermentación (Quijano, Figueroa-González \& Buitrón, 2018).

\section{Ciclo del azufre (Metabolismo de las SOM y PARTICIPACIÓN EN EL CICLO DEL AZUFRE)}

El ciclo del azufre es un proceso biogeoquímico importante y se caracteriza por reacciones de oxidación y reducción que permite además que los microorganismos se puedan beneficiar al obtener energía (Tourna, Maclean, Condron, O'Callaghan \& Wakelin, 2014), (Figura 1). Este proceso es de suma importancia, ayuda a comprender la biodesulfuración del biogás y la participación de los microorganismos responsables de este procedimiento. En términos de reducción, el sulfato acepta un electrón para convertirse posteriormente en sulfuro, sin embargo, cuando ocurren reacciones de oxidación; los sulfuros donan electrones que convierten a estos compuestos 
1. Alicyclobacillus, Acidithiobacillus sp.

2. Thiobacillus, Beggiatoa.

\section{Desulfuromonas.}

4, 5. Desulfovibrio.

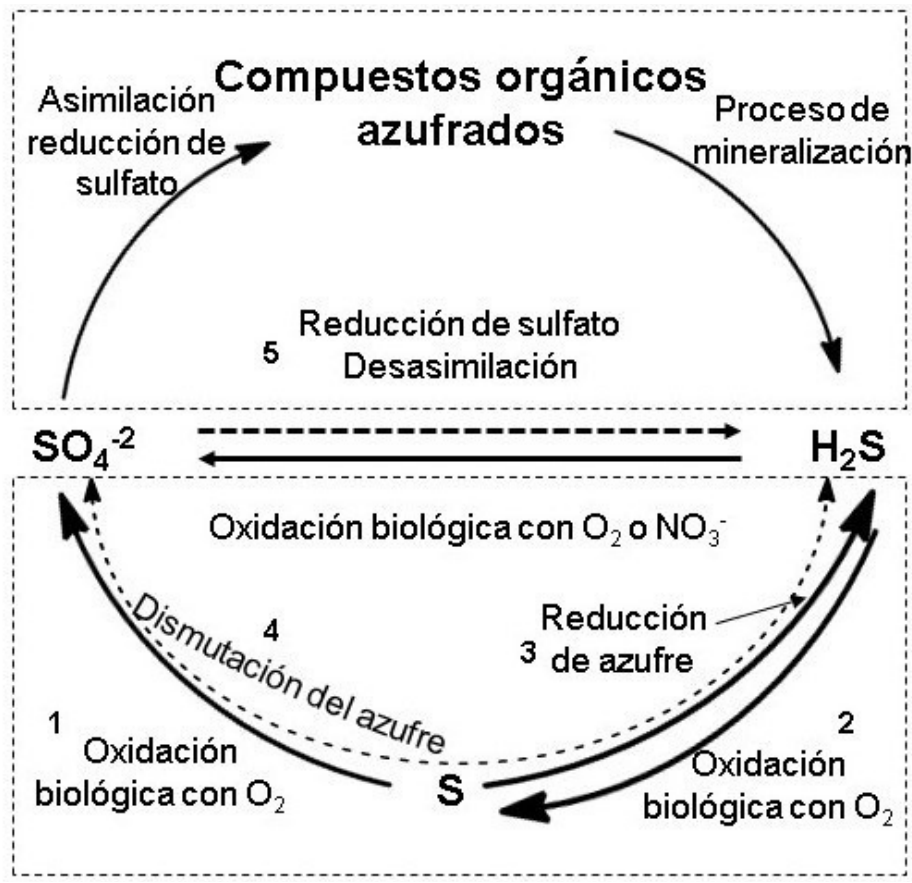

Proceso aerobio

Proceso anaerobio

Figura 1. Ciclo del azufre. Proceso de oxidación y reducción de compuestos de azufre y algunas bacterias participantes.

en azufre elemental o sulfato, mediante bacterias fototróficas o quimiolitotróficas (Barbusiński \& Kalemba, 2016).

La oxidación del azufre a sulfato es el proceso de mayor relevancia durante el ciclo del azufre y algunos microorganismos pueden realizar esta acción. En el dominio Arquea, los sulfolobales pueden oxidar azufre aeróbicamente; en el dominio Eucarya, hongos del género Aurebosidium, Aspergillus y Penicillium; en tanto en el dominio Bacteria, los géneros litótrofos y fotótrofos como Bacillus, Thiobacillus, Beggiatoa, Thiothrix, Thermothix, Thiovolum, Acidianus, Sulfolobus, Thioalcalimicrobium y Thioalkallividrio, tienen la capacidad de oxidar el azufre, algunas de manera aerobia y/o anaerobia (Gholipour et al., 2018). Otros de los microorganismos oxidantes del azufre son Thiomonas, Acidiphilium, Thiomicrospira, Thiovulum y Thioploca (Kambam, Soundararajan, Raghupati \& Mathivanan, 2015).

Las SOB pueden ser de dos tipos: fotosintéticas y no fotosintéticas. Las primeras oxidan el azufre en ausencia del oxígeno con el uso de luz y poseen pigmento, a diferencia de las no fotosintéticas que carecen de color y pueden oxidar compuestos de azufre con presencia de oxígeno, así como de modo anaerobio mediante el nitrato (Rawat \& Rawat, 2015).

Las bacterias con mejores ventajas biotecnológicas para la oxidación de sulfuro a sulfato o azufre elemental (biodesulfuración), son las de tipo quimiolitotróficas debido a su alta afinidad a los compuestos del azufre. En contraste, las bacterias fotosintéticas requieren de energía luminosa y estar en soluciones transparentes obligatoriamente, en cambio, las bacterias fototróficas producen sulfuro de manera interna, lo que conllevaría a varios procesos para su remoción, todo ello ocasiona un costo elevado a gran escala (Barbusiński \& Kalemba, 2016). Es importante conocer las características principales de cada bacteria con la finalidad de identificarla y conocer su rol en la oxidación del azufre.

Las bacterias que participan en la oxidación de sulfuro/azufre de manera aerobia son del género Thiobacillus, Achromatium y Beggiatoa y pueden oxidar el $\mathrm{H}_{2} \mathrm{~S}$ a azufre elemental hasta sulfato, en cambio, anaeróbicamente bacterias del género Thioploca y Thiothrix lo hacen de manera anaerobia (Madigan, Martinko, Dunlap \& Clark, 2009). Las bacterias del género Thiobacillus son bacilos Gram negativos, obligadas quimiolitotróficas, desnitrificadores facultativos (Thiobacillus thioparus, T. neopalitanus, T. denitrificans), acidófilos extremos ( $T$. thiooxidans), acidófilos oxidantes de hierro ferros (T. ferrooxidans) y halófilos (T. halophilus), (Kambam et al., 2015). En el caso de Achromatium son cocos de tamaño aproximado de 10-100 $\mu \mathrm{m}$, quimiolitotrófico oxidante del azufre (Madigan et al., 2009). En cambio, el género Beggiatoa tiene la capacidad de formar filamentos motiles y en presencia de $\mathrm{H}_{2} \mathrm{~S}$ depositan azufre de manera intracelular (Vidyalakshmi, Paranthaman \& Bhakyaraj, 2009). 
Estos microorganismos son mayormente mesófilos y pueden ser aislados de lugares con un rango de $4-95{ }^{\circ} \mathrm{C}$ y crecen en condiciones de $\mathrm{pH}$ neutro, ácido y básico $>7.5$ (Rawat \& Rawat, 2015). Thioploca y Thiothrix (mixótrofo aerobio estricto) son bacterias oxidadoras de azufre, filamentosas, que llevan a cabo esta acción en ausencia de oxígeno junto con la reducción de nitrato hasta amonio (Madigan et al., 2009).

Bacterias del género Desulfovibrio y Desulfobacter participan en la reducción del sulfato de manera anaerobia a $\mathrm{H}_{2} \mathrm{~S}$. Desulfovibrio sp. (no acetato oxidante), contiene desulfoviridina, es un bacilo curvo con flagelos polares Gram negativo, no productor de esporas y termófilo. En cambio, Desulfobacter sp. (acetato oxidante), es un bacilo con flagelo polar único Gram negativo, no contiene desulfoviridina, oxida el acetato como donador de electrones a $\mathrm{CO}_{2}$ por el ciclo de Krebs. Algunas bacterias como las Desulfuromonas pueden reducir el azufre anaeróbicamente hasta sulfuro. Son bacilos rectos, Gram negativos, anaerobios estrictos, utilizan etanol acetato o succinato como donador de electrones, son bacterias desasimiladoras. Otros de los procesos son la dismutación del azufre, es decir, producción de $\mathrm{H}_{2} \mathrm{~S}$ y sulfato a partir de tiosulfato, por bacterias del género Desulfovibrio; oxidación o reducción de compuestos orgánicos azufrados y la desulfuración, de azufre orgánico a $\mathrm{H}_{2} \mathrm{~S}$ (Madigan et al., 2009).

En cuanto a las vías metabólicas relacionadas a la oxidación del azufre, las bacterias oxidantes de este elemento cuentan con tres: vía de oxidación del azufre por Paracoccus, vía de oxidación del tiosulfato y la vía intermediaria del tetrationato. La primera está relacionada con un sistema enzimático SOx asociado a la bacteria quimiolitotrófica facultativa Alphaproteobacteria, la segunda involucra la interacción de un sistema enzimático SOx y reductasa desasimiladora de sulfito y la tercera es característica de bacterias quimiolitotróficas obligadas como Acidithiobacillus sp. y Thiobacillus (Tourna et al., 2014).

\section{USO DE LA METAGENÓMICA PARA LA IDENTIFICACIÓN DE SOM}

La biodiversidad microbiana es pilar del funcionamiento de todo ecosistema; por lo que es importante comprender la estructura y funciones de estas comunidades, incluyendo las variaciones que pueden ocurrir en respuesta a los factores ambientales que pueden modificarlas. Por medio de la microbiología tradicional se pueden identificar estos microorganismos, sin embargo, otras herramientas que han tomado auge, dentro de las ciencias "omicas" es la metagenómica. Desde 1998, cuando apareció por primera vez este término, se han magnificado los estudios sobre la identificación de microorganismos en diversos ecosistemas, especialmente aquellos que no son cultivables en el laboratorio, mediante el empleo del gen 16S rARN (Solera del Rio, 2014). Este gen es el marcador más utilizado para la identificación bacteriana cuya longitud de 1,500 pb contiene nueve regiones variables intercaladas entre regiones conservadas. Las regiones variables son frecuentemente utilizadas para la clasificación filogenética como asignación de género o especie en diversas comunidades microbianas (Support Illimina, s. f.; Cortés-López, Montor-Antonio, Olvera-Carranza, Peña-Castro \& Del Moral-Ventura, 2014). Además de esto, la metagenómica proporciona acceso a la diversidad genética global de las comunidades microbianas y su dinámica, es decir cambios de poblaciones en función del tiempo y el espacio (Solera del Rio, 2014). Todo esto permite obtener información relevante para el estudio de fenómenos de simbiosis, competición, comunicación entre microorganismos y su papel sobre la catálisis de los ciclos biogeoquímicos y de los procesos de biodegradación de compuestos xenobióticos, así como las nuevas funciones génicas relacionadas con el papel de los microorganismos en la modificación del medio ambiente (Castillo-Rodríguez, 2005).

Particularmente la metagenómica tiene una amplia incidencia en estudios ecológicos de regiones poco comunes y/o de importancia ambiental como: aguas termales, regiones salinas, mar Mediterráneo, regiones árticas, compostas, suelos contaminados, regiones oligotróficas, etc. (CortésLópez et al., 2014). Precisamente en aguas residuales, suelos de estanques, minas, residuos de efluentes de papel, entre otros se han identificado SOB (Kambam et al., 2015). Gros (2017) logró identificar Thiovulum sp., un género de bacteria épsilon oxidante del azufre a partir de sedimento de manglar marino rico en sulfuro. Para ello, extrajo DNA a partir de la muestra con el kit de extracción DNEasy y se realizó una amplificación por PCR del gen 16S rRNA utilizando cebadores universales 8F-1492R y 533F-1492R. Los resultados del análisis de secuenciación (1,320 bp) se utilizaron para realizar un análisis filogenético y por último la hibridación in situ por fluorescencia para comprobar la presencia de la proteobacteria.

Por otro lado, Cúcio, Overmars, Engelen \& Muyzer (2018) realizaron un análisis metagenómico de la rizósfera de pasto marino para la identificación de comunidades microbianas oxidantes de azufre mediante una secuenciación masiva Ilumina HiSeq 2000. El análisis bioinformático permitió identificar a las Gammaproteobacteria, Deltaproteobacteria y Alphaproteobacteria.

En tanto, D'Auria et al. (2018) identificaron bacterias oxidantes del azufre a partir de muestras de sedimento, biovermiculita y esnotita de una cueva con presencia de agua rica en azufre. La amplificación de las regiones variables V1 y V3 del gen 16S rRNA, la pirosecuenciación y el análisis bioinformático revelaron la presencia de Proteobacteria y Acidobacteria, entre otras con menor proporción. 
Existe poco conocimiento acerca del gran número de bacterias oxidantes de azufre (LSB), que habitan en aguas subterráneas sulfurosas en los grandes lagos. Por tal motivo, Sharrar et al. (2017) condujeron un análisis metagenómico del lago Huron, en donde se encontraron dos familias de LSB: Beggiatoaceae que son filogenéticamente intermedias entre grupos conocidos de agua dulce y marinos. Varias de estas Beggiatoaceae tenían 16S rRNA genes que contenían intrones previamente observados en taxones marinos. En la zona Alpena, abundaban Thiothrix lacustris y Thiothrix spp. Se identificaron los genes de oxidación de azufre mediante la ruta rDsr, oxidación de $\mathrm{H}_{2}$ vía Ni-Fe hidrogenasas y el uso de $\mathrm{O}_{2}$ y nitrato como aceptores de electrones. Actualmente se tiene el conocimiento de una macro-bacteria aislada del sulfureto Humboldt de Chile, este microorganismo se identificó por metagenómica como Candidatus Venteriaishoeyi que está relacionado con formas no-vacuolares como en Beggiatoa (Fonseca et al., 2017).

Las comunidades microbianas encontradas en aguas subterráneas ricas en azufre en Estados Unidos, llamadas LowerKane Cave, WY, USA y Glenwood Hot Springs, $\mathrm{CO}$, USA, revelan la presencia de $\varepsilon$-proteiobacterias y $\gamma$-proteobacterias, que incluyen grupos relacionados con Sulfurovum, Sulfurospirillum, Thiothrixy un grupo $\varepsilon$-proteiobacteriano sin parentesco cercano (Rossmassler, Hanson, \& Campbell, 2016)

\section{BIOENERGía Y COSTOS DE PRODUCCIÓN}

El incremento en la generación de residuos agroindustriales ha ocasionado interés en su aprovechamiento, pues al ser biodegradables y con grandes cantidades de biomasa se han utilizado para la generación de bioenergía. El costo de producir biogás se estima en dos partes, el costo de capital y el operacional. El primero es estimado por $\mathrm{m}^{3}$ de 300 a 800 dólares americanos (USD), 2,400-7,500 USD por kWe, 5,000-7,500 USD, por conceptos de capacidad del digestor, instalaciones eléctricas y por el volumen de biogás producido por hora $\left(\mathrm{Nm}^{3} / \mathrm{h}\right)$. Ahora bien, por purificarlo la inversión varia de 1,950 a 2,600 USD porNm ${ }^{3} / \mathrm{h}$ (Caruso et al., 2019). Por otro lado, el costo por unidad de biogás tratado puede oscilar entre 0.025 a $0.046 \mathrm{USD} / \mathrm{m}^{3}$, considerando la inversión anual por adsorbentes (1,281-13,500 USD), (Abatzoglou \& Boivin, 2009). A pesar de que la producción de bioenergía es redituable, a nivel industrial se necesitan optimizar los parámetros de pretratamiento del sustrato, purificación del biogás, entre otras para que se refleje como un verdadero costo-beneficio (Achinas et al., 2017).

Alrededor del mundo, la producción de biocombustibles es bien vista, Estados Unidos seguido de Brasil, Europa, China y Canadá, representan la mayor producción de bioetanol con un total de 23.4 billones de galones. En cuanto al biodiesel, algunos países de Europa como Alemania, Francia, España,
Italia y Polonia, son los principales productores a nivel mundial, seguido de Brasil, Argentina, Estados Unidos y China, los cuales a lo largo de los años han aumentado la producción de este biocombustible, llegando a producir en 2013, 6,289 millones de galones. Sin embargo, China es considerado el principal productor de biogás con 6 billones $\mathrm{Nm}^{3}$ anualmente (Guo et al., 2015). Sin embargo, países como India, Canadá, Tailandia, Estonia, China, Corea del Sur, Brasil, Sudáfrica, también son productores de biometano (Svensson, 2013). En América Latina Colombia, Perú, Bolivia, México entre otros también han producido biogás (Reyes, 2017).

\section{CONCLUSiOnes}

La producción de bioenergía a partir de residuos agroindustriales debe ser una estrategia aplicada en los países para ir cambiando paulatinamente el uso de combustibles fósiles, pues reduce costos, es accesible, es renovable y no afecta al medio ambiente. Es importante tener en cuenta que la purificación biológica del biogás para la recuperación de un buen rendimiento del biometano conlleva a la identificación de los microorganismos con capacidad metabólica para desulfurar el biogás, permitiendo tener cepas que pudieran ser modificadas genéticamente para aplicaciones industriales.

\section{Agradecimientos}

Al Tecnológico Nacional de México por el financiamiento del proyecto 6694.18-P “Análisis metagenómico de suelo y aguas termales azufradas: búsqueda de microorganismos con potencial biotecnológico en el área agroindustrial" aprobado en la modalidad profesores reconocidos en el SNI.

\section{REFERENCIAS}

Abatzoglou, N. \& Boivin, S. (2009). A review of biogas purification processes. Biofuels, Bioproducts \& Biorefining, 3, 42-71. https://doi.org/10.1002/bbb.117

Achinas, S., Achinas, V. \& Euverink, G. J. W. (2017). A technological overview of biogas production from biowaste. Engineering, 3(3), 299-307. https://doi. org/10.1016/J.ENG.2017.03.002

Antonelli, J., Lindino, C. A., Rodrigues de Azevedo, J. C., Melegari de Souza, S. N., Cremonez, P. A. \& Rossi, E. (2016). Biogas production by the anaerobic digestion of whey. Revista de Ciências Agrárias, 39(3), 463-467. https://doi.org/10.19084/RCA15087

Asif, M. \& Muneer, T. (2007). Energy supply, its demand and security issues for developed and emerging economies. Renewable and Sustainable Energy Reviews, 11(7), 1388-1413. https://doi.org/10.1016/j.rser.2005.12.004

Awe, O. W., Zhao, Y., Nzihou, A., Minh, D. P. \& Lyczko, N. (2017). A review of biogas utilization, purification and upgrading technologies. Waste and Biomass Valorization, 8(2), 267-283. https://doi.org/10.1007/s12649-016-9826-4

Barbusiński, K. \& Kalemba, K. (2016). Use of biological methods for removal of $\mathrm{H}_{2} \mathrm{~S}$ from biogas in wastewater 
treatment plants-a review. Architecture Civil Engineering Environment, 9(1), 103-112.

Barrera, E. L., Spanjers, H., Dewulf, J., Romero, O. \& Rosa, E. (2013). The sulfur chain in biogas production from sulfate-rich liquid substrates: A review on dynamic modeling with vinasse as model substrate. Journal of Chemical Technology and Biotechnology, 88(8), 14051420. https://doi.org/10.1002/jctb.4071

Basurto, S. \& Escalante, R. (2012). Impacto de la crisis en el sector agropecuario en México. ECONOMIÍAunam, 9(25), 51-73.

Caruso, M., Braghieri, A., Capece, A., Napolitano, F., Romano, P., Galgano, F., Altieri, G. \& Genovese, F. (2019). Recent Updates on the Use of Agro-Food Waste for Biogas Production. Applied Sciences, 9(6), 1217. https://doi.org/10.3390/app9061217

Castillo-Rodríguez, F. (2005). Biotecnología Ambiental. Madrid, España: Tébar.

Castro, J. (2011). Perspectivas de la demanda energética global. Petrotecnia, 11(1), 54-70. Retrieved from http:// www.petrotecnia.com.ar/febrero2011/sin/Demanda.pdf

Chakravarty, G. (2016). Evaluation of fruit wastes as substrates for the production of biogas. Scholars Research Library Annals of Biological Research, 7(3), 25-28. Retrieved from http://scholarsresearchlibrary.com/archive.html

Chu, S. \& Majumdar, A. (2012). Opportunities and challenges for a sustainable energy future. Nature, 488(7411), 294 303. https://doi.org/10.1038/nature11475

Cortés-López, N., Montor-Antonio, J., Olvera-Carranza, C., Peña-Castro, J. \& Del Moral-Ventura, S. (2014). Metagenómica: una ventana de oportunidad a nuevos genes y genomas microbianos. Revista Iberoamericana de Ciencias, 1(7), 45-58. Retrieved from www.reibci.org

Cúcio, C., Overmars, L., Engelen, A. H. \& Muyzer, G. (2018). Metagenomic Analysis Shows the Presence of Bacteria Related to Free-Living Forms of Sulfur-Oxidizing Chemolithoautotrophic Symbionts in the Rhizosphere of the Seagrass Zostera marina. Frontiers in Marine Science, 5(May), 1-15. https://doi.org/10.3389/fmars.2018.00171

Cury, R. K., Aguas, M. Y., Martínez, M. A., Olivero, V. R. \& Chams, Ch. L. (2017). Residuos agroindustriales su impacto, manejo y aprovechamiento Agroindustriales waste impact, management and exploitation. Revista Colombiana de Ciencia Animal, 9, 122-132. https://doi. org/10.24188/recia.v9.nS.2017.530

D’Auria, G., Artacho, A., Rojas, R. A., Bautista, J. S., Méndez, R., Gamboa, M. T., Gamboa, J. R. \& GómezCruz, R. (2018). Metagenomics of bacterial diversity in villa Luz caves with sulfur water springs. Genes, 9(1), 1-13. https://doi.org/10.3390/genes9010055

Díaz-Rodríguez, Y., Acosta-Díaz, S., Barrios-San Martín, Y., Pascual Mustelier-Pérez, S., Contrera-Aviléz, R. \& González-Hernández, F. (2017). Caracterización de un consorcio bacteriano sulfooxidante aislado de un sistema de Biofiltración de gas natural. In Revista CENIC Ciencias Biológicas, (Vol. 48). Retrieved from https:// www.redalyc.org/pdf/1812/181250961005.pdf

Diep, N. Q., Sakanishi, K., Nakagoshi, N., Fujimoto, S., Minowa, T. \& Tran, X. D. (2012). Biorefinery: concepts, current status, and delevopment trends. International Journal of Biomass \& Renewables, 2(1), 1-8.

Elaiyaraju, P. \& Partha, N. (2016). Studies on biogas production by anaerobic process using agroindustrial wastes. Research in Agricultural Engineering, 62(2), 7382. https://doi.org/10.17221/65/2013-rae

ESAMUR. (2011). Del Análisis del Biogás a la Planta de Generación (MWM Energy. Eficiency. Environment, ed.). Retrieved from http://www.esamur.com/public/file/ ponencia136.compressed.pdf

Escalante, S. R. I. \& Catalán, H. (2008). Situación actual del sector agropecuario en México: perspectivas y retos. Economía Informa, 350, 7-25.

Fonseca, A., Ishoey, T., Espinoza, C., Pérez-Pantoja, D., Manghisi, A., Morabito, M., Salas-Burgos, A. \& Gallardo, V. A. (2017). Genomic features of "Candidatus Venteria ishoeyi”, a new sulfur-oxidizing macrobacterium from the Humboldt Sulfuretum off Chile. PLoS ONE, 12(12), e0188371. https://doi.org/10.1371/journal.pone.0188371

Forster-Carneiro, T., Isaac, R., Pérez, M., \& Schvartz, C. (2012). Anaerobic Digestion: pretreatments of substrates. In A. Mudhoo (Ed.), Biogas Production: pretreatment methods in anaerobic digestion (pp. 1-20). New Jersey: John Wiley \& Sons.

Gholipour, S., Mehrkesh, P., Azin, E., Nouri, H., Rouhollahi, A. A. \& Moghimi, H. (2018). Biological treatment of toxic refinery spent sulfidic caustic at low dilution by sulfuroxidizing fungi. Journal of Environmental Chemical Engineering, 6(2), 2762-2767. https://doi.org/10.1016/j. jece.2018.04.026

Gomez, C. D. C. (2013). Biogas as an energy option: an overview. In A. Wellinger, J. Murphy \& D. Baxter (Eds.), The Biogas Handbook: Science, production and applications (pp. 1-16). Cambridge: Woodhead Publishing.

Grande-Tovar, C. D. (2016). Valorización biotecnológica de residuos agrícolas y agroindustriales. Cali: Bonaventuriana.

Gros, O. (2017). First description of a new uncultured epsilon sulfur bacterium colonizing marine mangrove sediment in the Caribbean: Thiovulum sp. strain karukerense. FEMS Microbiology Letters, 364, 1-8. https://doi.org/10.1093/ femsle/fnx 172

Guo, M., Song, W. \& Buhain, J. (2015). Bioenergy and biofuels: History, status, and perspective. Renewable and Sustainable Energy Reviews, 42, 712-725. https://doi. org/https://doi.org/10.1016/j.rser.2014.10.013

Hossain, A. B. M. S. \& Mekhled, M. A. (2010). Biodiesel fuel production from waste canola cooking oil as sustainable 
energy and environmental recycling process. Australian Journal of Crop Science, 4(7), 543-549.

Hublin, A., Schneider, D. R. \& Dzodan, J. (2014). Utilization of biogas produced by anaerobic digestion of agroindustrial waste: Energy, economic and environmental effects. Waste Management and Research, 32(7), 626633. https://doi.org/10.1177/0734242X14539789

Ingale, S., Joshi, S. J. \& Gupte, A. (2014). Production of bioethanol using agricultural waste: banana pseudo stem. Brazilian Journal of Microbiology, 45(3), 885-892.

Kambam, V., Soundararajan, D., Raghupati, S. \& Mathivanan, S. (2015). Comparative Study of Sulphur Oxidizing Bacteria Isolated from Different Comparative Study of Sulphur Oxidizing Bacteria Isolated from Different Wastes. International Journal of Extensive Research, $12,1-7$.

Llaneza, H., Moris, M. A., González Azpíroz, L. \& González, E. (2010). Caracterización, Purificación y Control del Biogás. In PSE PROBIOGAS (Ed.), Estudio de la Viabilidad de Sistemas de Purificación y Aprovechamiento de Biogás (p. 28). Retrieved from http://213.229.136.11/ bases/ainia_probiogas.nsf/0/7559B244B63EB155C1257 53F0058E255/\$FILE/Cap1.pdf

Madigan, M. T., Martinko, J. M., Dunlap, P. V. \& Clark, D. P. (2009). Brock: Biología de los microorganismos. Madrid: Pearson Education.

Mejías-Brizuela, N., Orozco-Guillén, E. \& GaláanHernández, N. (2016). Aprovechamiento de los residuos agroindustriales y su contribución al desarrollo sostenible de México. Revista de Ciencias Ambientales y Recursos Naturales, 2(6), 27-41. Retrieved from www.ecorfan. org/spain

Moreno-Andrade, I., Moreno, G. \& Quijano, G. (2019). Theoretical framework for the estimation of $\mathrm{H}_{2} \mathrm{~S}$ concentration in biogas produced from complex sulfurrich substrates. Environmental Science and Pollution Research. https://doi.org/10.1007/s11356-019-04846-3

Mussatto, S. I., Ballesteros, L. F., Martins, S. L. F. \& Teixeira, J. A. (2012). Use of agro-industrial wastes in solidstate fermentation processes. In S. Kuan-Yeow \& G. Xinxin (Eds.), Industrial Waste (pp. 121-140). Croatia: InTechOpen.

Naz, S., Ahmad, N., Akhtar, J., Ahmad, N. M., Ali, A. \& Zia, M. (2016). Management of citrus waste by switching in the production of nanocellulose. IET Nanobiotechnology, 10(6) 395-399. https://doi.org/10.1049/iet-nbt.2015.0116.

Ortega-Viera, L., Crespo-Artigas, A., Gandón-Hernández, J., Rodríguez-Muñoz, S., Fernández-Santana, E. \& Ameneiros-Martínez, J. M. (2017). Modelo fenomenológico que describe el proceso de purificación de biogás empleando membranas de zeolita natural. Revista Mexicana de Ingeniería Química, 16(2), 531-539.

Ortega, V. L., Rodríguez, M. S., Fernández, S. E. \& Bárcenas, P. L. (2015). Principales métodos para la desulfuración del biogás. Ingeniería Hidráulica $y$ Ambiental, 36(1), 45-56.

Padilla de la Rosa, J. D., Ruiz-Palomino, P., Arriola-Guevara, E., García-Fajardo, J., Sandoval, G. \& GuatemalaMorales, G. M. (2018). A Green process for the extraction and purification of hesperidin from mexican lime peel (Citrus aurantifolia Swingle) that is extendible to the citrus genus. Processes, 6(266), 1-13.

Palma-López, D. J., Zavala-Cruz, J., Cámara-Reyna, J. C., Ruiz-Maldonado, E. \& Salgado-García, S. (2016). Uso de residuos de la agroindustria de la caña de azúcar (Saccharum spp.) para elaborar abonos orgánicos. Agroproductividad, 9(7), 29-34.

Pinto, L. \& Quipuzco, L. (2015). Aprovechamiento de aguas residuales domésticas para producción de biogás y biol, mediante digestores de carga diaria. Anales Cientificos, 76(1), 87-93. https://doi.org/10.21704/ac.v76i1.768

Ponce, E. (2016). Métodos sencillos en obtención de biogás rural y su conversión en electricidad. IDECIA (Chile), 34(5), 75-79. https://doi.org/10.4067/s071834292016005000011

Quijano, G., Figueroa-González, I. \& Buitrón, G. (2018). Fully aerobic two-step desulfurization process for purification of highly H2S-laden biogas. Journal of Chemical Technology and Biotechnology, 93(12), 35533561. https://doi.org/10.1002/jctb.5732

Quirino, C., Duana, A., Hernández, M. \& García, G. (2016). Desarrollo económico del sector agropecuario en México a 20 años de la firma TLCAN. Revista TECSISTECATL, 8(20), 1-20.

Ramaraj, R. \& Dussadee, N. (2015). Biological purification processes for biogas using algae cultures: a review. International Journal of Sustainable and Green Energy, 4(1), 20-32. https://doi.org/10.11648/j. ijrse.s.2015040101.14

Rasool, U. \& Hemalatha, S. (2016). A review on bioenergy and biofuels: sources and their production. Brazilian Journal of Biological Sciences, 3(5), 3. https://doi.org/10.21472/ bjbs.030501

Rawat, R. \& Rawat, S. (2015). Colorless sulfur oxidizing bacteria from diverse habitats. Advances in Applied Science Research, 6(4), 230-235.

Reyes, A. E. A. (2017). Generación de biogás mediante el proceso de digestión anaerobia, a partir del aprovechamiento de sustratos orgánicos. Revista Cientifica de FAREM-Estelí. Medio Ambiente, Tecnología y Desarrollo Humano, 6(24), 60-81.

Rossmassler, K., Hanson, T. \& Campbell, B. (2016). Diverse sulfur metabolisms from two subterranean sulfidic spring systems. FEMS Microbiology Letters, 363(16), fnw162(18). https://doi.org/10.1093/femsle/fnw162.

Rubiano-Labrador, C., Hurtado, A. H. \& Salamanca, J. I. (2018). Búsqueda de bacterias oxidadoras de azufre para su potencial uso en la producción de biogás de alta 
pureza. Revista de Investigación Agraria y Ambiental, 9(2), 295-304.

Safdar, M. N., Kausar, T., Jabbar, S., Mumtaz, A., Ahad, K. \& Saddozai, A. A. (2017). Extraction and quantification of polyphenols from kinnow (Citrus reticulate L.) peel using ultrasound and maceration techniques. Journal of Food and Drug Analysis, 25, 488-500.

San-Valero, P., Penya-roja, J. M., Javier Álvarez-Hornos, F., Buitrón, G., Gabaldón, C. \& Quijano, G. (2019). Fully aerobic bioscrubber for the desulfurization of $\mathrm{H}_{2} \mathrm{~S}-$ rich biogas. Fuel, 241, 884-891. https://doi.org/10.1016/j. fuel.2018.12.098

Sánchez-Aldana, D., Aguilar, C. N., Nevarez-Moorillon, G. V., \& Esquivel-Contreras, J. C. (2013). Comparative extraction of pectin and polyphenols from mexican lime pomace and bagasse. American Journal of Agricultural and Biological Science, 8(4), 309-322.

Sarabia-Méndez, M., Laines-Canepa, J., Sosa-Oliver, J. \& Escalante-Espinosa, E. (2017). Producción de biogás mediante codigestión anaerobia de excretas de borrego y rumen adicionadas con lodos procedentes de una planta de aguas residuales. Revista Internacional de Contaminación Ambiental, 33(1), 109-116. https://doi. org/10.20937/RICA.2017.33.01.10

Sharrar, A. M., Flood, B. E., Bailey, J. V, Jones, D. S., Biddanda, B. A., Ruberg, S. A.,Marcus, D. N. \& Dick, G. J.(2017). Novel large sulfur bacteria in the metagenomes of groundwater-fed chemosynthetic microbial mats in the Lake Huron basin. Frontiers in Microbiology, 8, Art 791. 1-15. https://doi.org/10.3389/ fmicb.2017.00791.

Singh, R.S. \& Walia, A. (2016). Biofuels Historical Perspectives and Public opinions. In RA Singh, A.
Pandey, \& E. Gnansounou (Eds.), Biofuels, Production and Future Perspective (1st editio, pp. 3-23). CRC Press.

Solera del Rio (2014). De Residuo a Recurso. El Camino hacia la Sostenibilidad. Ediciones Mundi-Prensa, Madrid, España.

Svensson, M. (2013). Biomethane for transport applications. In A. Wellinger, J. Murphy, \& D. Baxter (Eds.), The Biogas Handbook: Science, production and applications (pp. 428-443). Cambridge: Woodhead Publishing.

Tapia-Gómez, A., Laines-Canepa, J. \& Sosa-Olivier, J. (2017). Codigestión de residuos sólidos orgánicos generados en las cafeterías de la División Académica de Ciencias Biológicas. Journal of Energy, Engineering Optimization and Sustainability, 1(1), 71-82. https://doi.org/10.19136/ jeeos.a1n1.1725

Tourna, M., Maclean, P., Condron, L., O’Callaghan, M. \& Wakelin, S. A. (2014). Links between sulphur oxidation and sulphur-oxidizing bacteria abundance and diversity in soil microcosms based on soxB functional gene analysis. FEMS Microbiology Ecology, 88(3), 538-549. https:// doi.org/10.1111/1574-6941.12323

Vargas-Corredor, Y. K. \& Pérez-Pérez, L. I. (2018). Aprovechamiento de residuos agroindustriales para el mejoramiento de la calidad del ambiente. Revista Facultad de Ciencias Básicas, 14(1), 59-72.

Vidyalakshmi, R., Paranthaman, R. \& Bhakyaraj, R. (2009). Sulphur oxidizing bacteria and pulse nutrition- a review. World Journal of Agricultural Sciences, 5(3), 270-278.

Yepes, S. M., Naranjo, L. J. M. \& Sánchez, F. O. (2008). Valorización de residuos agroindustriales- frutas- en Medellín y el sur del Valle del Aburrá, Colombia. Revista Facultad Nacional de Agronomía Medellín, 61(1), 4422-4431. 